\title{
Genome-wide analysis of the GH3 family in apple (Malus $\times$ domestica)
}

\author{
Huazhao Yuan, Kai Zhao, Hengjiu Lei, Xinjie Shen, Yun Liu, Xiong Liao and Tianhong Li
}

\begin{abstract}
Background: Auxin plays important roles in hormone crosstalk and the plant's stress response. The auxinresponsive Gretchen Hagen3 (GH3) gene family maintains hormonal homeostasis by conjugating excess indole-3 -acetic acid (IAA), salicylic acid (SA), and jasmonic acids (JAs) to amino acids during hormone- and stress-related signaling pathways. With the sequencing of the apple (Malus $\times$ domestica) genome completed, it is possible to carry out genomic studies on GH3 genes to indentify candidates with roles in abiotic/biotic stress responses.

Results: Malus sieversii Roem., an apple rootstock with strong drought tolerance and the ancestral species of cultivated apple species, was used as the experimental material. Following genome-wide computational and experimental identification of $M d G H 3$ genes, we showed that MdGH3s were differentially expressed in the leaves and roots of $M$. sieversii and that some of these genes were significantly induced after various phytohormone and abiotic stress treatments. Given the role of GH3 in the negative feedback regulation of free IAA concentration, we examined whether phytohormones and abiotic stresses could alter the endogenous auxin level. By analyzing the GUS activity of DR5::GUS-transformed Arabidopsis seedlings, we showed that ABA, SA, salt, and cold treatments suppressed the auxin response. These findings suggest that other phytohormones and abiotic stress factors might alter endogenous auxin levels.

Conclusion: Previous studies showed that GH3 genes regulate hormonal homeostasis. Our study indicated that some GH3 genes were significantly induced in M. sieversii after various phytohormone and abiotic stress treatments, and that ABA, SA, salt, and cold treatments reduce the endogenous level of axuin. Taken together, this study provides evidence that $\mathrm{GH} 3$ genes play important roles in the crosstalk between auxin, other phytohormones, and the abiotic stress response by maintaining auxin homeostasis.
\end{abstract}

Keywords: Malus sieversii Roem, Phytohormone, Biotic stress, GH3, DR5, GUS

\section{Background}

Auxin regulates numerous aspects of plant growth and development. To date, auxin has been linked to the control of cell elongation and division, tropic responses to light and gravity, general root and shoot architecture, organ patterning, responses to biotic and abiotic stimuli, vascular development, and growth in tissue culture [1]. Phytohormones are involved in many distinct and/or overlapping processes throughout the life cycle of plants. Auxin facilitates hormonal crosstalk by regulating the expression of auxin-responsive genes [2]. For example,

\footnotetext{
* Correspondence: lith@cau.edu.cn

Department of Fruit Science, College of Agriculture and Biotechnology/Key Laboratory of Stress Physiology and Molecular Biology for Tree Fruits of Beijing, China Agricultural University, 2 Yuanmingyuan West Road, Haidian District, Beijing 100193, People's Republic of China
}

several ACS genes, which encode enzymes involved in ethylene biosynthesis, are induced by auxin [3,4]. Auxin homeostasis and the auxin response pathway are regulated by several groups of auxin-responsive genes, including the Gretchen Hagen3 (GH3) family. Jasmonate resistant 1 (Jar1) belongs to the GH3 gene family in Oryza sativa (rice) and is involved in jasmonate signaling [5]. In addition, $A t G H 3-5$ acts as a bifunctional modulator of both salicylic acid (SA) and auxin signaling during pathogen infection [6]. Auxin also regulates the expression of several genes in the gibberellic acid (GA) biosynthesis pathway [7]. Moreover, auxin homeostasis links growth regulation with stress adaptation responses. For instance, plants subjected to stress conditions exhibit retarded growth, altered patterns of metabolism, and changes in the expression and/or activity of auxin-regulated genes 
$[8,9]$. Furthermore, the repression of auxin signaling in Arabidopsis enhances antibacterial resistance [10].

Auxin homeostasis and the auxin response pathway are regulated by several groups of auxin-responsive genes, including the Gretchen Hagen3 (GH3) family [2]. GH3 was first identified in Glycine max (soybean) as an early auxin-responsive gene [11]. To date, GH3 homologs have been indentified in Chlorophyta, Bryophyta, Coniferophyta, and Magnoliophyta [12]. GH3 family genes are divided into three groups (I, II, and III) based on their sequence similarities and the substrate specificities of their products in Arabidopsis, which harbors 19 GH3 members and one incomplete GH3 protein. $[13,14]$. Group I GH3 enzymes are JA-amido or SAamido synthetases [14]. Arabidopsis Group II enzymes were demonstrated to be active on IAA [13,15]. Group III enzymes have only been identified in Arabidopsis to date. Group II GH3 functions in the negative feedback regulation of IAA concentration. Several Arabidopsis Group II GH3s help maintain auxin homeostasis by conjugating excess IAA to amino acids, either for storage or degradation [15]. Members of this gene family are known to be regulated by phytohormones and biotic/ abiotic stress factors, including abscisic acid (ABA), SA, JA, drought, cold, salt, pathogen infection, and light [6,16-19]. GH3-mediated auxin homeostasis is an essential constituent of the complex network of auxin activity that regulates stress adaptation responses [19]. Recent research has shown that overexpression of $\mathrm{GH} 3$ reduced auxin content and changed plant architecture and plant resistance to biotic and abiotic stress. Overexpression of TLD1/OsGH3.13 in the rice tld1-D mutant resulted in IAA deficiency, dramatic changes in plant architecture, and enhanced drought tolerance [6]. Overexpression of OsGH3.1 and OsGH3.8 in rice resulted in reduced auxin content, arrested plant growth and development, abnormal plant morphology, and enhanced pathogen resistance $[20,21]$.

Apple is one of the most widely cultivated fruit trees in the world, and is thus of considerable economic value. Because biotic/abiotic stresses are crucial factors in determining the distribution and yield of apple trees, improving resistance to stresses has been one of the main breeding objectives in apple. $M$. sieversii, an apple rootstock with strong drought tolerance, is an ancestral species of modern apple cultivars that is mainly distributed in the Tianshan Mountains of Central Asia [22,23]. Previous studies in Arabidopsis and rice indicated that GH3 is involved in the stress response pathway by maintaining auxin homeostasis through conjugating excess IAA to amino acids. In fruit trees, our knowledge of GH3 genes is mainly limited to their roles in fruit development. Vitis vinifera (grapevine) GH3-1 encodes an IAA-amido synthetase involved in the establishment and maintenance of low
IAA concentrations, which enables fruit ripening [24]. Apple GH3 genes were down-regulated during rapid fruit expansion, consistent with the elevated concentrations of auxin observed at this stage [25].

Synthetic auxin-responsive promoters, such as DR5 [26], are widely used as experimental readouts for the auxin response and/or auxin levels in planta [27]. DR5:: GUS contains several copies of a synthetic auxinresponsive element (TGTCTC) fused to a $35 \mathrm{~S}$ minimum promoter and the GUS encoding sequence [26]. To investigate the role of $G H 3$ genes in apple, we examined the expression patterns of these genes in $M$. sieversii under biotic and abiotic stress conditions and analyzed whether other phytohormones and abiotic stresses could alter the endogenous distribution of auxin using DR5:: GUS-transformed Arabidopsis seedlings. We show that GH3 genes play important roles in the crosstalk between auxin, other phytohormones, and abiotic stress factors in M. sieversii by maintaining auxin homeostasis.

\section{Results}

\section{Genome-wide characterization of the $M$. domestica GH3 family}

From the peptide FASTA file of $M$. domestica genome annotations, we identified 29 candidate GH3 family proteins using the HMMER 3.0 (28 March 2010) program. We disregarded seven of the candidates, as they were below the E-value threshold after the first round of searching. Furthermore, two sequences were repeats of each other, another four sequences were incomplete, with overlapping regions that could be combined into two complete GH3 sequences, and four members were found not to be GH3 family proteins using the BLASTp program at the National Center for Biotechnology Information. Therefore, 15 unique members were present, all of which were confirmed to be GH3 family proteins by the hidden Markov model of the SMART/Pfam tool. Among these full-length coding sequences, four MdGH3 genes (MdGH3-1, 3, 4, and 5) were further confirmed by RT-PCR amplification, cloning, and sequencing (Additional file 1). The MdGH3 polypeptide sequences were all of uniform length (Table 1) and the deduced molecular weight of MdGH3 proteins generally ranged from 64 to $69 \mathrm{kDa}$. Multiple sequence alignments showed that the MdGH3s were highly conserved (Additional file 2). All of the MdGH3s contained a highly conserved GH3 domain that did not match any other motif in the Pfam database. Pairwise analyses of the full-length protein sequences showed that the overall sequence identities ranged from $26.9 \%$ to $96.8 \%$ (Additional file 3). Interestingly, MdGH3s formed homeologous pairs, with the sequence identities of homeologous pairs being extremely high; e.g., MdGH3-1/MdGH3-2 (94.4\%), MdGH3-3/MdGH3-4 (94.3\%), MdGH3-5/MdGH3-6 (96.8\%), MdGH3-7/MdGH3-8 (94\%), 
Table 1 Characteristics of the GH3 family in M. domestica

\begin{tabular}{|c|c|c|c|}
\hline Name & $\mathrm{GDR}^{\mathrm{a}}$ & Length $(a a)^{b}$ & ESTs/cDNAsc \\
\hline$\overline{M d G H 3-1}$ & MDP0000834656 & 607 & GO524295.1 \\
\hline $\mathrm{MdGH} 3-2$ & MDP0000226842 & 607 & 0 \\
\hline MdGH3-3 & MDP0000132162 & 614 & 0 \\
\hline $\mathrm{MdGH} 3-4$ & MDP0000402444 & 614 & DT002305.1 \\
\hline MdGH3-5 & MDP0000873893 & 601 & CN915524.1 DT043059.1 EB141323.1 DR991447.1 CO898207.1 \\
\hline MdGH3-6 & MDP0000209432 & 601 & $\begin{array}{c}\text { CN914672.1 EB156443.1 CN908490.1 EB156630.1 EB155796.1 EB144806.1 CV632081.1 } \\
\text { CV128791.1 CN995533.2 EB155616.1 EB155541.1 EB156184.1 EB156696.1 EB156293.1 } \\
\text { EB156251.1 }\end{array}$ \\
\hline MdGH3-7 & MDP0000872868 & 599 & CN910272.1 CN909305.1 CN907800.1 CN910152.1 CN909148.1 CN910072.1 \\
\hline MdGH3-8 & MDP0000612660 & 599 & CN909842.1 CN907795.1 CN907829.1 CN907847.1 CN908348.1 CN908044.1 \\
\hline MdGH3-9 & MDP0000204381 & 596 & CV082641.1 CV082778.1 \\
\hline $\mathrm{MdGH} 3-10$ & MDP0000568498 & 596 & 0 \\
\hline MdGH3-11 & MDP0000786650 & 571 & CN489575.1 \\
\hline MdGH3-12 & MDP0000233483 & 571 & $\begin{array}{c}\text { CN912573.1 CN900696.1 GO511018.1 GO528185.1 DY256317.1 CN909380.1 EB141581.1 } \\
\text { EB123692.1GO528114.1 DY255512.1 EB151573.1 EB156721.1 EH034514.1 GO538786.1 } \\
\text { EB107177.1 CV631737.1 CV630750.1 EB107168.1 CO899232.1 EB107459.1 GO516821.1 } \\
\text { EB107154.1 EB107308.1 EB107425.1 GO535202.1 EB107113.1 CN934444.1 } \\
\text { EB107348.1EB107290.1 DR992460.1 CN933788.1 CN934593.1 }\end{array}$ \\
\hline MdGH3-13 & MDP0000811081 & 589 & $\begin{array}{c}\text { GO523947.1 EB109814.1 GO514230.1 CN879199.1 GO510774.1 CN931693.1 GO534539.1 } \\
\text { CN445458.1 CN926457.1 DR993803.1 }\end{array}$ \\
\hline MdGH3-14 & $\begin{array}{l}\text { MDP0000214081 } \\
\text { MDP0000238173 }\end{array}$ & 589 & 0 \\
\hline MdGH3-15 & MDP0000231245 & 575 & G0522926.1 GO522429.1 G0522817.1 \\
\hline
\end{tabular}

${ }^{\mathrm{a} A c c e s s i o n}$ numbers of the proteins at the Genome Database for Rosaceae. ${ }^{\mathrm{b}}$ Length of the protein in amino acids. ${ }^{\mathrm{c}} \mathrm{Accession}$ numbers of the ESTs/cDNAs at NCBI.

MdGH3-9/MdGH3-10 (95.3\%), MdGH3-11/MdGH3-12 (86.9\%), and MdGH3-13/MdGH3-14 (94.2\%). Then, we examined the phylogenetic relationship and exon-intron organization of apple GH3 family members. As shown in Figure 1, the homeologous pairs exhibited a close evolutionary relationship and similar gene structures. All of the MdGH3 genes contained two or three introns, and most had a similar intron phase distribution. We also analyzed the chromosomal location of $M d G H 3 s$, and found that all $15 \mathrm{MdGH3s}$ were distributed on 10 of 17 chromosomes. Four MdGH3 genes were present on chromosome 11 , including a distinct tandem duplicate gene cluster with two tandem genes (MdGH3-9 and $M d G H 3-15$, respectively); two were present on chromosome 3 and also on 5 ; and one each on chromosomes 1, 4, 7, 9, 13, 15, and 17 . None of the $M d G H 3$ genes were located on chromosomes $2,6,8,10,12,14$, or 16 . Twelve of $15 \mathrm{MdGH3s}$, including homeologous pairs $M d G H 3-1 / M d G H 3-2, M d G H 3-3 / M d G H 3-$ 4, MdGH3-9/MdGH3-10, and MdGH3-11/MdGH3-12, were mapped on the segmental duplication regions according to information from the SyMAP database (Figure 2).

\section{MdGH3 promoter and EST analyses}

Cis-acting regulatory DNA elements on both strands of the $M d G H 3$ promoter were identified using the PLACE web server (http://www.dna.affrc.go.jp/PLACE/), and different DNA elements predicted to be involved in the plant's response to phytohormones and biotic and abiotic stress were found. The DNA elements included multiple copies of CACGTG (ABA-inducible); TGTCTC (ARF (auxin response factor) binding site); ACTTTA (tissue-specific expression and auxin-inducible); CATATG (auxin-inducible); TGACG (IAA/SA-inducible); TTGAC (SA-inducible); AACGTG (JA-inducible); ACGTG and CACATG (drought-inducible); CCGAC (cold/drought-inducible); GAAAAA (salt-inducible); and TGTGA, AAAGAT, and TTGACC (disease-inducible) (see Additional file 4). A BLASTn search of the $M$. domestica EST database (324847 records), which is available at the NCBI webserver (http:// blast.ncbi.nlm.nih.gov/), confirmed the transcriptional activity of most $M d G H 3 s$, but the frequency of ESTs for individual genes varied greatly (Table 1). For example, 32 ESTs were identified for MdGH3-12 and 15 for MdGH3-6, whereas no ESTs had been deposited for MdGH3-2, 3, 10, and 14 (Table 1).

\section{Phylogenetic relationship between $M$. domestica and Arabidopsis GH3 family members and AtGH3 expression analysis using Genevestigator}

Before analyzing the expression pattern of $M d G H 3 s$, we performed a preliminary study of AtGH3 expression. To 


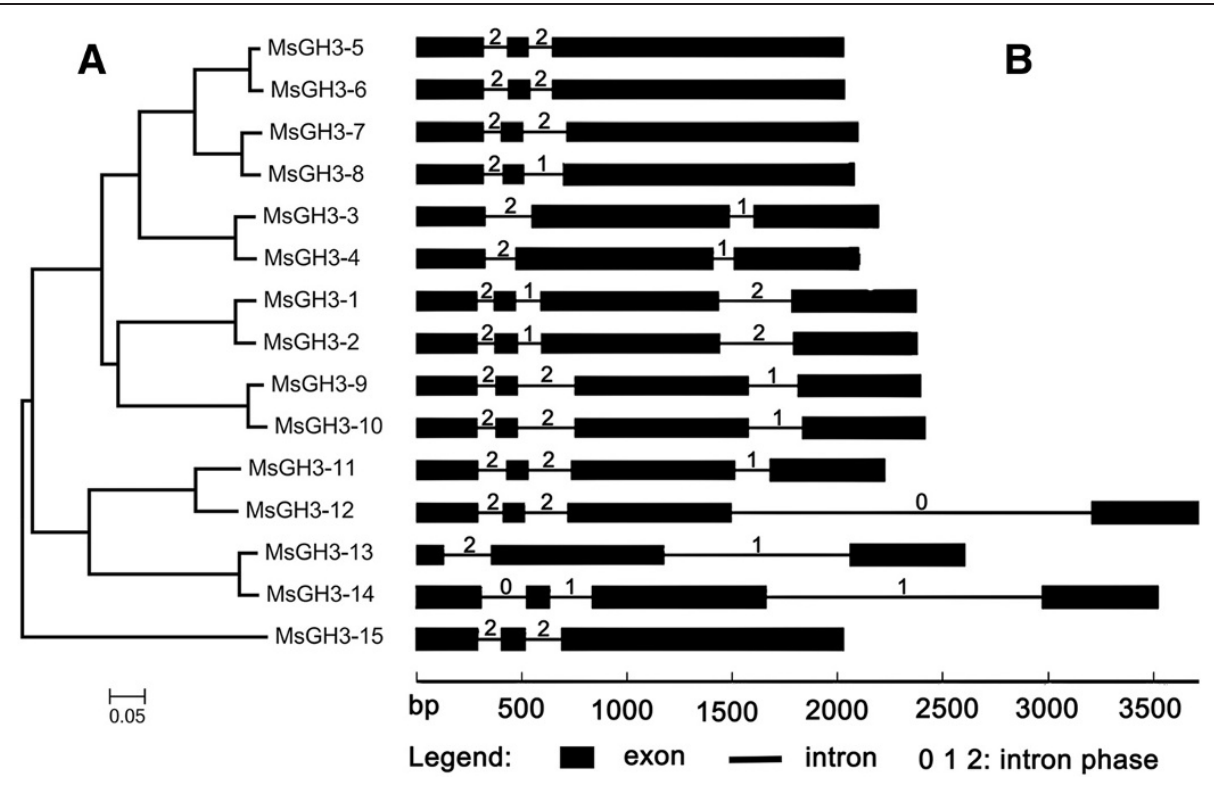

Figure 1 Phylogenetic analysis and gene structure of apple GH3 members. A Phylogeny of apple GH3 proteins, generated using MEGA5 (using the neighbor-joining method and a bootstrap test with 1000 iterations). B Gene structure of the corresponding apple GH3 proteins, generated by a gene structure display server. The black boxes represent exons and lines represent introns. 0, 1, and 2 represent phase 0 , 1, and 2 introns.

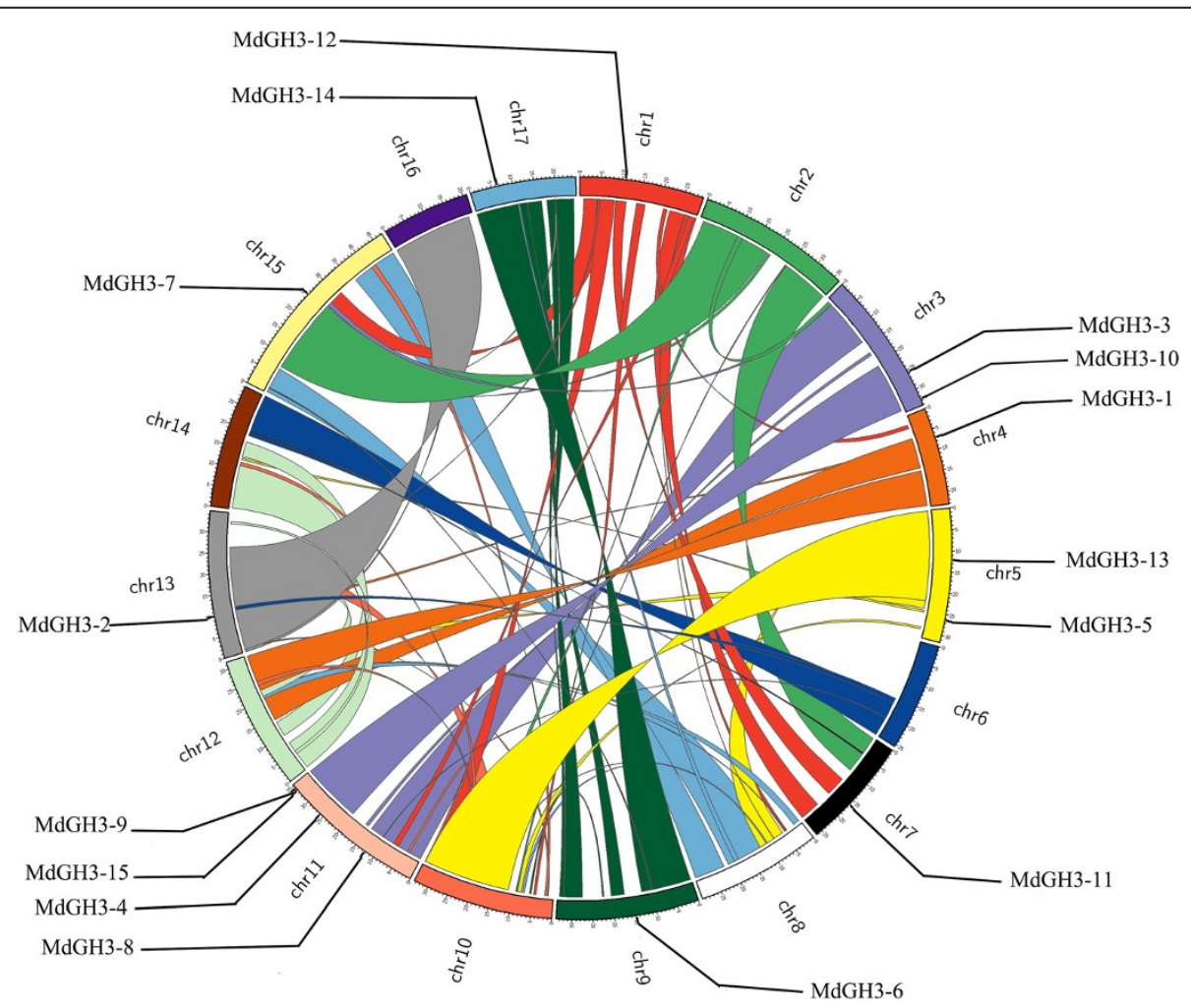

Figure 2 Mapping of $M d G H 3 s$ and segmental duplication regions on apple chromosomes. Segmental duplication regions were determined using the SyMAP database. Genes and segmental duplication regions were mapped to the apple chromosomes via the Circos tool. The apple chromosomes were arranged in a circle. Ribbon links represent segmental duplication regions. 
examine the phylogenetic relationship between $M$. domestica and Arabidopsis GH3 family members, a phylogenetic tree was constructed from alignments of their full-length protein sequences. Whereas AtGH3s can be clustered into three sequence homology groups [13], MdGH3 proteins are only present in two of these (Group I and II; Figure 3). Most of the AtGH3/MdGH3 proteins showed a 1:2 orthologous relationship, such as AtGH3-17 from Arabidopsis and the gene pair from apple, MdGH3-1 and -2. Based on the Arabidopsis microarray data, we found that many of the AtGH3s were significantly up-regulated under phytohormone and biotic/abiotic stress treatment (Additional file 5). Most Arabidopsis Group II enzymes were induced by auxin; AtGH3.1, AtGH3.2, AtGH3.3, and AtGH3.4 were elevated over 10-fold after IAA treatment and AtGH3.5 and $A t G H 3.6$ were induced to a lesser extent (2.5-fold to 8-fold). AtGH3.9 and AtGH3.17 expression exhibited no remarkable changes in response to auxin. In contrast, no members of the other two groups showed an obvious response to auxin. Only three AtGH3 members (AtGH3-3, AtGH3-5, and AtGH3-6; all belonging to Group II) were induced over 3-fold within $3 \mathrm{~h}$ of ABA treatment. AtGH3-3 and AtGH3-4 were slightly induced (under 3fold) under SA and methyl jasmonate (JA) treatments.
Upon cold treatment, AtGH3-4 expression increased over 7-fold in the green tissue, and AtGH3-12 was elevated over 10 -fold in the root. After drought treatment, only AtGH3-14 was induced over 6-fold in the root, while the other members had no remarkable response. In response to heat, $A t G H 3-3$ and $A t G H 3-10$ increased over 3 -fold. Salinity treatment caused a marked induction of AtGH3-1, AtGH3-3, AtGH3-4, and AtGH3-12 expression in the root. All treatments considered, AtGH3-3 and AtGH3-4 responded to most of phytohormone and abiotic stresses, while some of the other AtGH3 respond to some treatments.

\section{Differential expression of $M d G H 3 s$}

To determine the expression level of $M d G H 3 s$, qRTPCR was performed with total RNA isolated from the leaf and root tissues of micropropagated $M$. sieversii plants. Given the high degree of sequence identity between homeologous pairs (Additional file 3), it was challenging to design optimal qRT-PCR primers that were specific for each gene. Since the primers designed for MdGH3-1 and MdGH3-10 were predicted to be unable to differentiate between the homeologues, the expression patterns are given with both names (see Additional file 1). The expression level of the apple HistoneH3 gene

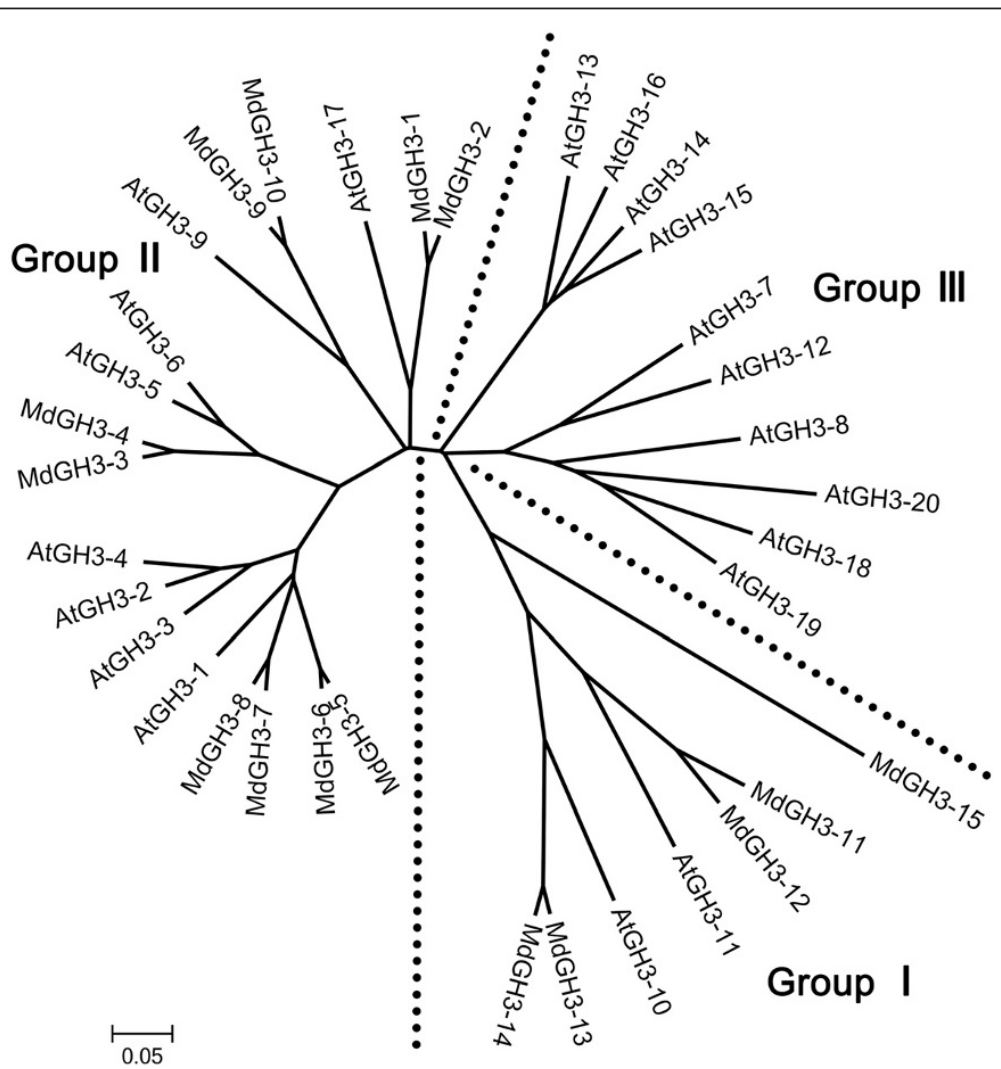

Figure 3 Phylogenetic tree of $\boldsymbol{M}$. domestica and Arabidopsis GH3 proteins. The phylogeny was constructed using the neighbor-joining method and a bootstrap test with 1000 iterations, using MEGA5 software, and alignments were generated with ClustalW. 


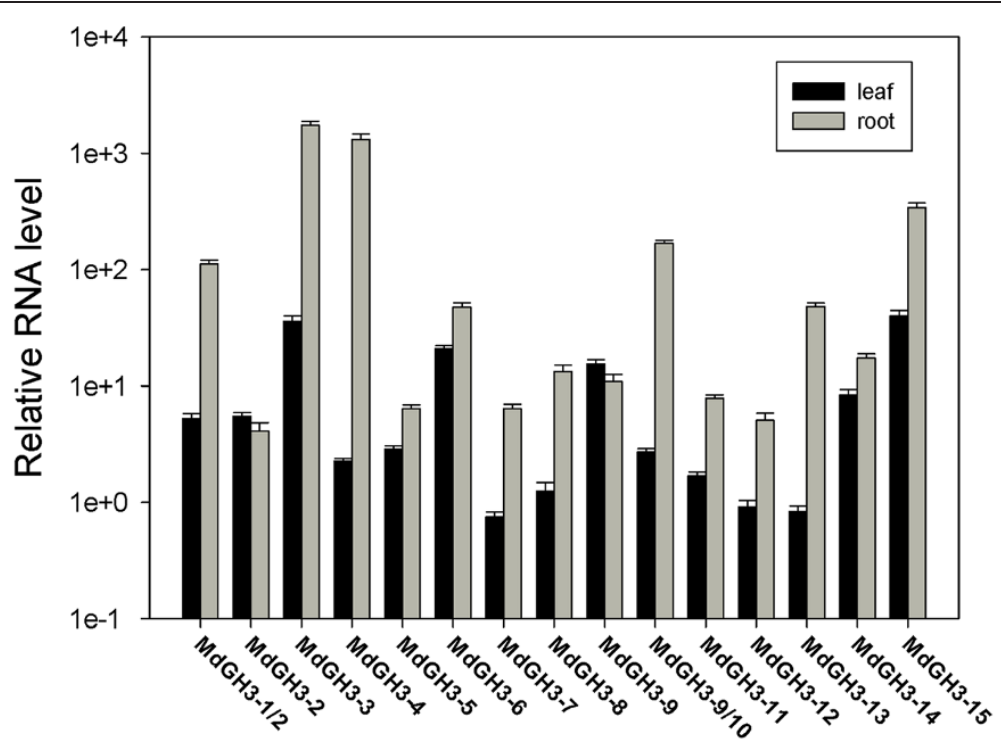

Figure 4 qRT-PCR analysis of $M d G H 3$ genes under normal growth conditions. Seedlings were grown on Hoagland solution for Data were normalized to the expression level of the apple HistoneH3 gene. The expression level of apple HistoneH3 was assumed to be $1 \mathrm{e}^{+5}$. Mean expression values were calculated from three independent replicates. Error bars represent the standard error of the mean.

was assumed to be $1 \mathrm{e}^{+5}$, and was selected as an internal standard in the analysis. qRT-PCR analysis revealed that $M d G H 3$ genes were differentially expressed in the leaves and roots (Figure 4 and Additional file 6). MdGH3-7, $M d G H 3-12$, and MdGH3-13 showed only weak expression in the leaves compared with MdGH3-3, MdGH3-6, MdGH3-9 and MdGH3-15. MdGH3-1/2, MdGH3-3 and $M d G H 3-4$ were strongly expressed in roots under natural growth conditions, compared with MdGH3-2, MdGH3-7, MdGH3-11, and MdGH3-12. Most MdGH3 genes were more strongly expressed in roots than in leaves, except for $M d G H 3-9$, suggesting that $M d G H 3$ genes are root-specific. In particular, $M d G H 3-4$ transcripts were over 500-fold higher in roots than in leaves. MdGH33 and $M d G H 3-15$ showed strong expression in both leaves and roots. However, MdGH3-2, MdGH3-5, MdGH3-7, MdGH3-11 and MdGH3-12 expression showed weak expression under normal growth conditions.

\section{Expression pattern of MdGH3s following phytohormone and abiotic stress treatment}

IAA treatment caused a dramatic induction of $M d G H 3-$ 6 and MdGH3-8 in both the leaves and roots, while the transcript level of MdGH3-2, MdGH3-11, MdGH3-13/14, and $M d G H 3-15$ was not remarkably changed in either of these tissues upon IAA treatment (Figure 5 and Additional file 7). MdGH3-1/2, MdGH3-3, MdGH3-5, and $M d G H 3-7$ were dramatically upregulated in the leaves only. In contrast, MdGH3-9 and MdGH3-9/10 were only induced in the roots under IAA treatment. The expression of most $M d G H 3$ genes was not remarkably changed after
ABA treatment in either the leaves or the roots, whereas the expression of $M d G H 3-3, M d G H 3-7$, and $M d G H 3-12$ in leaves and $M d G H 3-3, M d G H 3-8, M d G H 3-11$, and MdGH3-15 in roots was 2 -fold that of the control, suggesting that all of these genes are ABA-responsive. Interestingly, the expression pattern of $M d G H 3 s$ was similar after SA and JA treatment. When SA or JA was applied, $M d G H 3-3$ and $M d G H 3-12$ were upregulated in both the leaves and roots, suggesting that MdGH3 proteins participate in the crosstalk between the SA and JA signaling pathways. In contrast, the expression of $M d G H 3-1 / 2, M d G H 3-4$, and $M d G H 3-13$ was not altered upon SA or JA treatment in either leaves or roots. The expression of $M d G H 3-7$, and $M d G H 3-11$ was upregulated only in leaves upon SA or JA treatment. Salinity treatment caused a dramatic induction of MdGH3-7(almost 50-fold), MdGH3-14 (over 70-fold) in the leaves and MdGH3-5 (almost 150-fold), MdGH3-6(almost 60-fold), MdGH3-8 (over 160-fold) in the root. Under cold conditions, most $M d G H 3$ genes were slightly upregulated, whereas the expression of $M d G H 3-5$ rose 39-fold in the leaves. Most $M d G H 3$ s showed a slight increase in expression in the leaves or roots. In contrast, $M d G H 3-4$ and $M d G H 3-5$ showed increased expression in both the leaves and roots, under drought stress. However, the expression of $M d G H 3-5$ was strongly induced in leaves (over 460-fold) and roots (over 2-fold) under drought treatment. Interestingly, MdGH3-5, MdGH3-6, MdGH3-7, and MdGH3-8 were markedly induced in the leaves or roots under IAA, salt, cold, and drought treatment, suggesting that these genes might function in the abiotic stress response. 


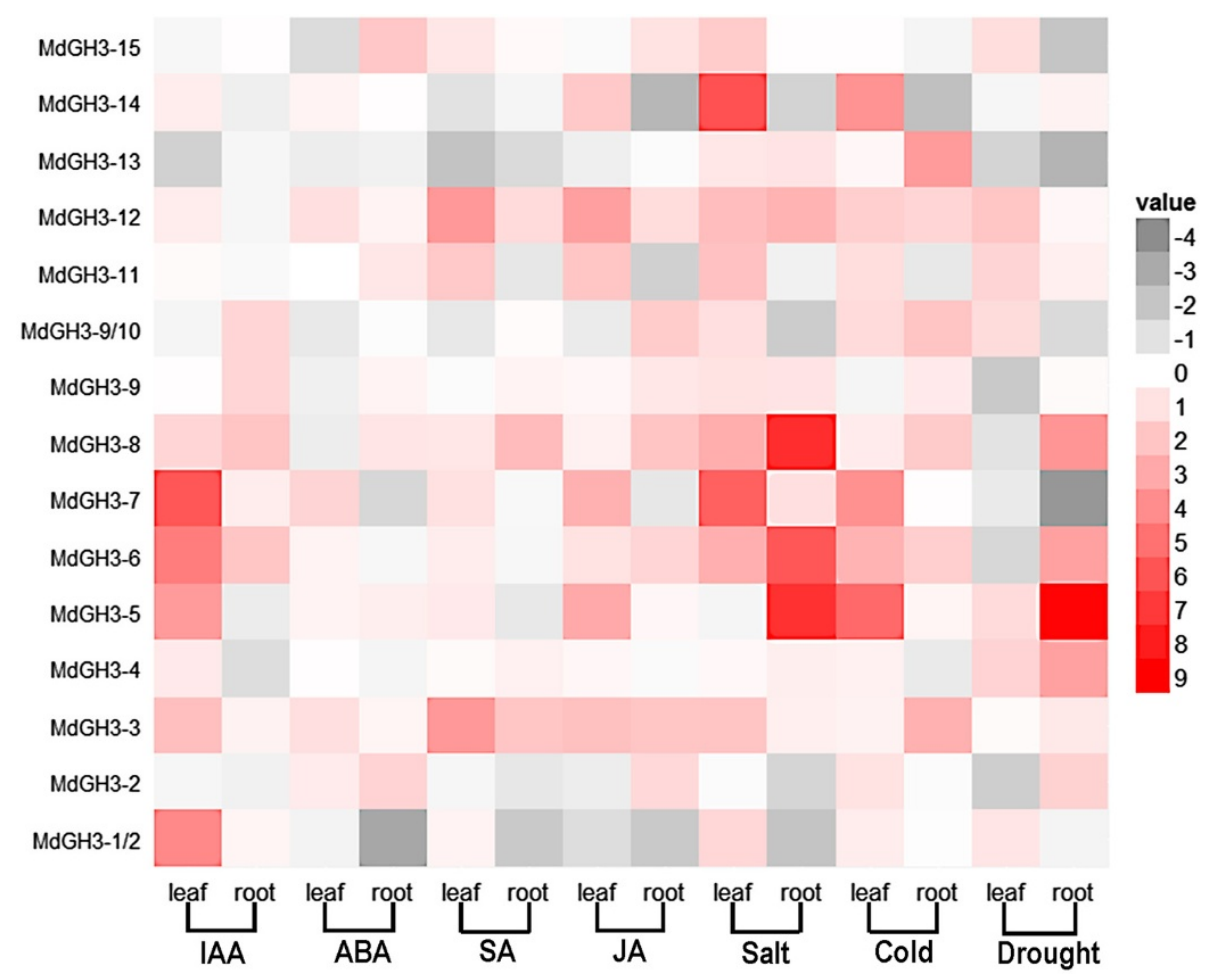

Figure 5 qRT-PCR analyses of $M d G H 3$ genes in plants subjected to various abiotic treatments. A heat map shows the relative RNA level of MdGH3 genes in plants under IAA, ABA, SA, JA, drought, cold, and salt treatments, compared to the basal expression level of MdGH3 genes in plants under normal growth conditions. Data were normalized to apple HistoneH3 gene expression. Fold difference was designated as the log2 value. The color scale representing the relative RNA level is shown to the right of the heat map.

\section{$\mathrm{ABA}, \mathrm{SA}$, salt, and cold treatments suppress the auxin response}

Auxin response elements (AuxREs), which consist of a TGTCTC motif and an adjacent or overlapping coupling element, were defined based on the auxin-responsive promoter of the soybean GH3 gene [28,29]). The finding that native and synthetic promoters containing this element are activated following auxin treatment $[29,30]$ led to the construction of artificial auxin-responsive promoters such as DR5 [31]. A fusion of the DR5 promoter with the $\beta$ glucuronidase (GUS) coding sequence has been frequently used as a maker to monitor endogenous auxin distribution and auxin levels in planta, because the resulting GUS activity coincides with the endogenous IAA distribution [32,33].

To determine whether other phytohormones and abiotic stresses could alter the endogenous distribution of auxin, we examined the response of the auxin-signaling reporter DR5::GUS to various plant hormones and abiotic stresses in Arabidopsis seedlings. As shown in Figure 6A and Additional file 8, treatment with $10 \mu \mathrm{M}$ IAA induced high levels of GUS activity relative to the control. This result was also observed upon in situ staining for reporter activity in roots, the organs in which the DR5 promoter is most active (Figure 7A). As shown in Figure 6B-E, ABA, SA, salt, and cold treatments significantly inhibited auxin-mediated expression of this reporter, and the same results were obtained upon in situ staining for GUS activity in roots (Figure 7B, C, E, and F). In the presence of $10 \mu \mathrm{M} \mathrm{ABA}$ or $0.1 \mathrm{mM} \mathrm{SA}$, the increase in GUS activity mediated by treatment with $10 \mu \mathrm{M}$ IAA was abolished, and this effect was more significant with increasing concentrations of ABA or SA. Likewise, upon incubation with $10 \mu \mathrm{M}$ IAA at $4^{\circ} \mathrm{C}$, GUS activity was significantly lower in the DR5::GUS seedlings than in the control. The effect of cold treatment on the suppression of the auxin response was more intense with longer treatments. Exposure to a low concentration of $\mathrm{NaCl}$ enhanced the auxin-mediated expression of GUS in DR5::GUS seedlings, whereas treatment with a high concentration of $\mathrm{NaCl}$ significantly inhibited auxinmediated GUS expression. However, as shown in Figure 7 D, JA treatment had no effect on the auxin-mediated expression of GUS in DR5:: GUS seedlings.

\section{Discussion}

Previous studies showed that the expression of GH3 family genes was regulated by various stress conditions $[6,8]$. Most studies of GH3 genes focused on the functional analysis of individual genes in Arabidopsis, rice, and grapevine $[18,21,24]$. With the availability of the whole genome 


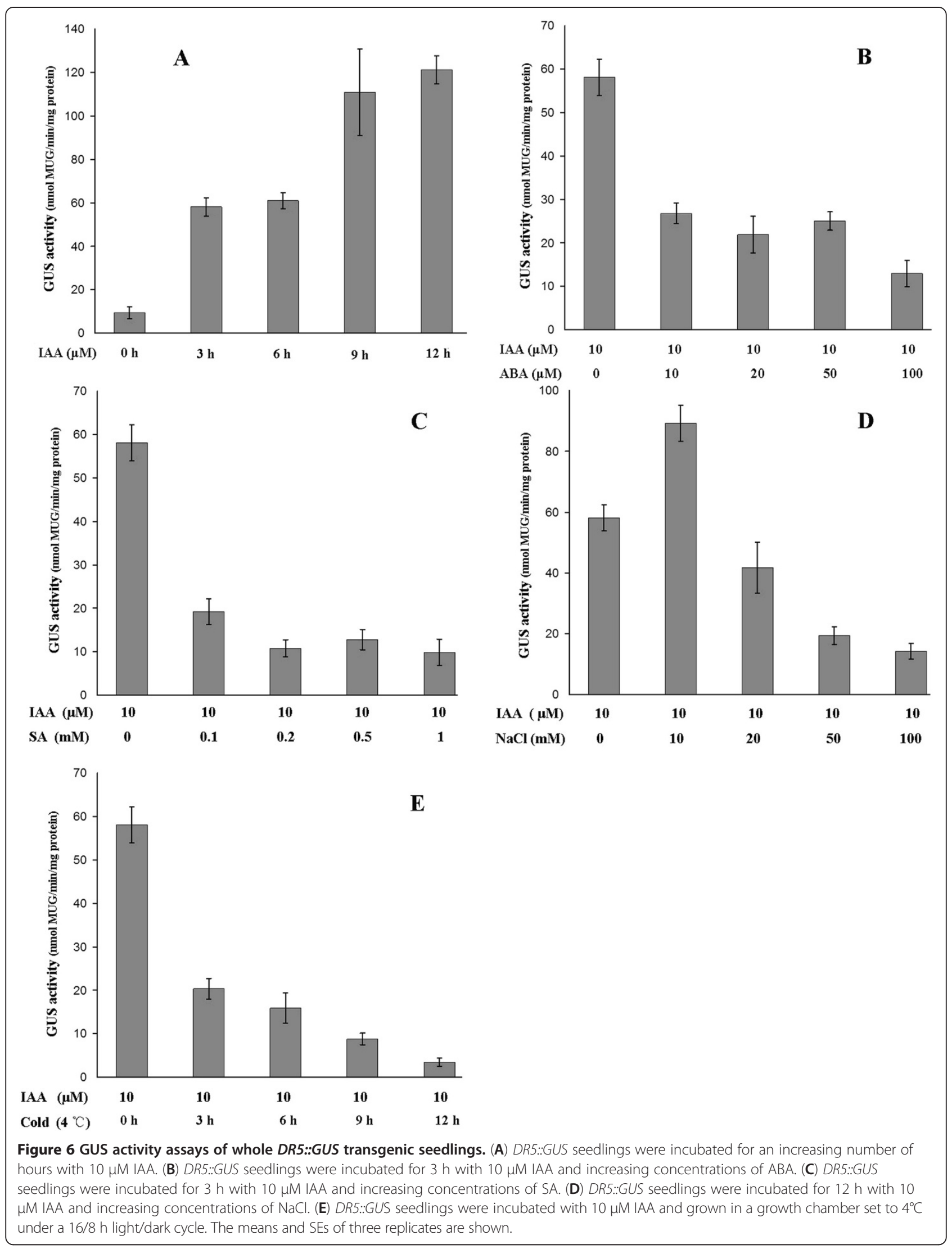




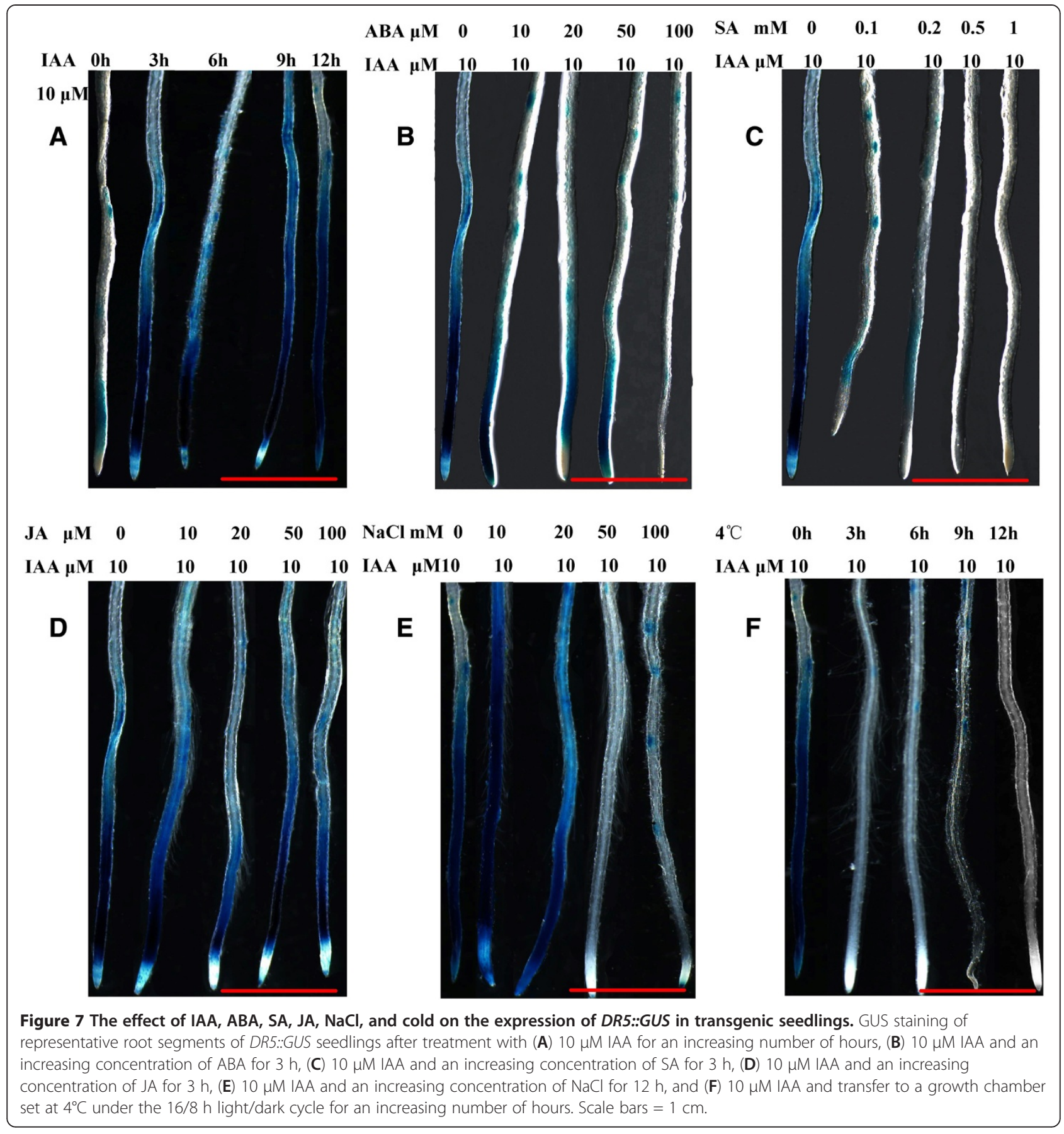

sequence for apple [34], complete gene families for different classes of genes can be readily identified from genome data based on knowledge of conserved domains. A systematic analysis of the characteristics and phylogeny of apple $G H 3$ family genes and of their expression patterns upon exposure to phytohormones and abiotic stress would help identify candidates with roles in abiotic/biotic stress responses. GH3-mediated auxin homeostasis is an essential constituent of the complex network that underlies crosstalk between auxin signaling and biotic/abiotic stress signaling [6,21]. We investigated whether other phytohormones and abiotic stresses could alter the endogenous auxin distribution using transgenic Arabidopsis seedlings expressing DR5::GUS. The results of these analyses will provide the groundwork for further studies on the role of auxin in stress responses.

\section{The evolution of GH3 family genes in apple}

In this study, we identified 15 putative proteins belonging to the GH3 family in apple (Table 1). The number of 
GH3 proteins in apple is similar to that in Arabidopsis (10; excluding Group III members, which are unique to Arabidopsis), rice (13), and Sorghum bicolor (sorghum) (16) $[13,19,35]$. Multiple sequence alignments showed that GH3s were highly conserved in apple (Additional file 2), as they are in sorghum [19]. Pairwise analyses with the full-length protein sequences showed that the overall amino acid sequence identities of the full-length GH3s were higher in apple (Additional file 3) than sorghum. MdGH3 genes emerged in homeologous pairs, with very high sequence similarity. The homeologous pairs had close evolutionary relationships and similar gene structures. Most of the MdGH3 homeologous pairs were also gene pairs in the segmental duplication regions, which suggests that the apple genome underwent duplication. Indeed, about 60 to 65 million years ago (Mya), the apple genome underwent a wholegenome duplication (GWD) event, which had a great impact on the amplification of members of gene families [34]. Moreover, these results also indicate that the members of an $M d G H 3$ homeologous pair might have descended from a common ancestor and have similar functions.

GH3 family genes were divided into three groups (I, II, and III) based on their sequence similarities and the substrate specificities of their products in Arabidopsis, which harbors $19 \mathrm{GH} 3$ members and one incomplete GH3 protein. Group III GH3 enzymes, of which there are nine in Arabidopsis, have only been identified in Arabidopsis to date $[13,15]$. Our phylogenetic analysis of Arabidopsis and apple GH3 proteins revealed three groups that exhibited distinct orthologous relationships, and no Group III enzymes in apple (Figure 3). Most of the AtGH3s/MdGH3 pairs showed a 1:2 orthologous relationship. Considering the total number of $G H 3$ family members, genomic duplications were not instrumental in the evolutionary history of the GH3 family in Arabidopsis [12]. In contrast, genomic duplications had a great impact on the amplification of members of the GH3 family in apple. This finding also indicates that MdGH3s might have begun to diversify as a result of gene duplication. Some AtGH3/MdGH3 pairs exhibited an $n: n$ orthologous relationship, which indicates that the functions of these family members had started to diversify in both Arabidopsis and apple. However, MdGH3-15 has distant orthologous relationships with the other GH3 proteins.

\section{GH3 family members involved in plant responses to phytohormones and abiotic stress}

To predict the functions of the $M d G H 3$ genes, we analyzed their promoters and ESTs. The promoters of MdGH3 contained numerous DNA elements predicted to be induced by phytohormones and biotic and abiotic stresses, suggesting that the expression of MdGH3s is regulated by phytohormones and biotic and abiotic stresses (see Additional file 4). Transcriptional activity was confirmed for most of the $M d G H 3 \mathrm{~s}$, and the frequency of ESTs implied that genes were expressed at various levels in different tissues (Table 1). Sequence homology analysis represents an important method for predicting gene function. Thus, we examined the expression patterns of $A t G H 3$ s under phytohormone and biotic/abiotic stress treatment, using the gene expression search engine, Genevestigator. Some of the GH3 family members responded to both phytohormones and abiotic stress in Arabidopsis (Additional file 4).

Our qRT-PCR analysis showed that almost all MdGH3s were expressed at a higher level in the roots than in the leaves under normal conditions, indicating that these proteins may be involved in root growth and development (Figure 4). The $y d k 1-D$ and $d f l 1-D$ Arabidopsis activationtagged mutants, which have a T-DNA insertion proximal to a Arabidopsis Group II GH3 gene, have short primary roots and a reduced number of lateral roots [13,17]. GH3 was first identified in Glycine $\max$ as an early auxinresponsive gene [11]. Many of the GH3 genes in Arabidopsis, soybean, and sorghum can be induced by applying exogenous auxin $[13,19,36]$. With the exception of GH3.1, all Group II GH3s in Arabidopsis were demonstrated to be IAA-amido synthetases [13]. In agreement with the $G H 3$ family expression pattern determined from Arabidopsis microarray data, all GH3 genes of Group II, except $M d G H 3-2$ and $M d G H 3-4$, were dramatically upregulated in apple under IAA treatment, suggesting that the Group II proteins from apple might also be IAAamido synthetases (Figure 5). However, the expression of most $M d G H 3$ genes was not markedly changed after ABA treatment. The expression of $M d G H 3-3, M d G H 3-7$, and $M d G H 3-12$ in the leaves and of MdGH3-2 and MdGH315 in the roots rose two-fold compared with the control, suggesting that all of these genes are involved in the ABA signaling pathway (Figure 5). SA and JA are known to play key roles in plant defense, and SA- and JA-dependent defense pathways exhibit crosstalk with each other [37-39]. Interestingly, the expression pattern of MdGH3 genes was similar under SA and JA treatment, which suggests that MdGH3s might participate in the crosstalk between SA- and JA-dependent defense pathways (Figure 5). In rice, wild-type seedlings subjected to various abiotic stresses showed a dramatic increase in the transcription of OsGH3-1, OsGH3-8, and OsGH3-13 compared with control seedlings [6,40]. In Arabidopsis, WES1 (AtGH3/ GH3.5) was strongly induced by ABA and SA treatment and pathogen infections [8]. In sorghum, $S b G H 3-1,2,4,5$, 12 , and 13 were markedly induced in leaves upon salt and drought stress treatments [19]. Previous studies showed that $G H 3$ genes were regulated by various phytohormones 
and biotic/abiotic stresses. Our analysis of microarray data from Arabidopsis revealed that AtGH3-3 and AtGH3-4 were induced by most phytohormone and abiotic stress treatments (Additional file 5). In this study, some $M d G H 3 s$ were markedly induced in response to various phytohormones and biotic/abiotic stress treatments, particularly MdGH3-5, MdGH3-6, MdGH3-7, and MdGH3-8 (Figure 5). Interestingly, our results showed that MdGH3-5, MdGH3-6, MdGH3-7, MdGH3-8, AtGH3-3, and $A t G H 3-4$ were close evolutionary relatives (Figure 3). Taken together, these findings suggest that the $M d G H 3$ gene family participates in the stress adaptation response, and that MdGH3-5, MdGH3-6, MdGH3-7, and MdGH3-8 may play important roles in this response.

\section{$A B A, S A$, salt, and cold treatments suppress the auxin response}

A comprehensive study of the effects of SA on auxin signaling based on the Affymetrix ATH1 Gene-Chip for Arabidopsis thaliana showed that SA causes the global repression of auxin-related genes, including the TIR1 receptor gene, resulting in the stabilization of Aux/IAA repressor proteins and the inhibition of auxin responses [41]. An R2R3-type $M Y B$ transcription factor, $M Y B 96$, regulates the drought stress response by integrating ABA and auxin signals. The MYB96-mediated ABA signals are integrated into an auxin signaling pathway that involves a subset of GH3 genes encoding auxinconjugating enzymes [42]. Previous studies indicated that $\mathrm{SA}$ and ABA have a negative impact on auxin responses. In addition, the $G H 3$ gene family can be regulated by phytohormones and biotic/abiotic stress, which act to regulate the auxin pool, effectively modulating auxin responses. We proposed that $\mathrm{SA}$ and $\mathrm{ABA}$ treatments induce $G H 3$ expression, which in return reduces the endogenous auxin level. We used DR5::GUS, an important tool for localizing regions of auxin responsiveness and/or auxin levels, to test this hypothesis. We detected the effect of various plant hormones and abiotic stress factors on the activity of this reporter in Arabidopsis seedlings. ABA, SA, salt, and cold treatments significantly inhibited the auxin-mediated expression of this reporter, confirming that endogenous auxin levels could indeed be suppressed by these treatments (Figures 6 and 7).

\section{Conclusion}

We performed a genome-wide analysis of the GH3 gene family in apple, conducted a phylogenetic analysis of the corresponding proteins, and examined their expression profiles in response to phytohormone and abiotic stress treatment. Some MdGH3 genes were markedly upregulated upon treatment with various phytohormones and biotic/abiotic stresses, especially $M d G H 3-5, M d G H 3-6, M d G H 3-7$, and $M d G H 3-8$, which were strongly induced in leaves following IAA, drought, cold, and salt treatment (Figure 5). ABA, SA, salt, and cold treatments caused a sharp decline in IAA concentration (Figures 6 and 7). Given that GH3 functions in the negative feedback regulation of IAA concentration, we conclude that other phytohormones and abiotic stress factors alter the endogenous distribution of auxin, and that the GH3 gene family plays an important role in this process by maintaining auxin homeostasis.

\section{Methods \\ Identification of GH3 proteins in the M. domestica genome}

The genome annotations of $M$. domestica were downloaded from the Genome Database for Rosaceae (http://www. rosaceae.org/node/476). GH3 proteins were identified by Hidden Markov Model (HMM) searches of sequences in the downloaded peptidic FASTA file using the HMMER 3.0 (28 March 2010) program [43] with default parameters. Any sequence that matched the GH3 (PF03321) domain was considered a candidate $\mathrm{GH} 3$ protein during the first round. Then, the results were submitted to the Pfam database to confirm that the candidate sequences were apple GH3 proteins. Similarity searches were performed using the BLASTp program at the National Center for Biotechnology Information (http://www.ncbi.nlm.nih.gov/blast/) to confirm the predictions.

\section{Sequence analysis and chromosomal mapping}

The sequence identities were analyzed by pairwise comparisons using the DNASTAR MegAlign 5.01 package. The number and position of exons and introns were determined by comparing the coding sequences (CDSs) with their corresponding genomic DNA sequences, and a map of the gene structure was generated using a gene structure display server [44]. The chromosomal position of each gene was retrieved from the position of the genes stored in the GFF file of the apple genome. Information regarding the segmental duplication regions in the apple genome was retrieved using the SyMAP database [45]. Then, genes and segmental duplication regions were mapped to the apple chromosomes using the Circos tool [46]. Multiple sequence alignments were performed using ClustalW [47]. Phylogenetic analysis was carried out by the neighbor-joining method using MEGA 5 software [48].

\section{MdGH3 promoters, EST detection, and AtGH3 expression analysis}

By comparing the CDSs with their corresponding genomic DNA sequences, regions approximately 2,000 bp upstream of the start codon were extracted from the genomic DNA sequences and were designated as promoter sequences. 
Cis-acting regulatory DNA elements on both strands of the promoter sequences were scanned using the PLACE webserver (http://www.dna.affrc.go.jp/PLACE/). BLASTn was used to perform a search for EST and cDNA sequences against the $M$. domestica EST database (324847 records) using the NCBI webserver (http://blast.ncbi.nlm.nih.gov/). Only hits of the BLASTn search for MdGH3 showing a bit score of at least 500 were considered to be significant. AtGH3s were downloaded from The Arabidopsis Information Resource (TAIR; http://arabidopsis.org). Based on Arabidopsis microarray data from public repositories such as ArrayExpress [49] and GEO [50], we determined the expression patterns of $A t G H 3 s$ under phytohormone and biotic/abiotic stress using the gene expression search engine of Genevestigator [51] (http://www.genevestigator.ethz.ch/).

\section{Plant materials, growth conditions, and treatments}

Arabidopsis thaliana DR5::GUS [26] and M. sieversii plants were used in this study.

The DR5::GUS transgenic plant has been described by Ulmasov [26]. Seedlings were surface sterilized with $10 \%$ sodium hypochlorite for $15 \mathrm{~min}$ and washed five times with sterile water. Sterilized seeds were cold treated for $4 \mathrm{~d}$ at $4^{\circ} \mathrm{C}$, germinated on 1/2 Murashige and Skoog medium (MS) with $0.8 \%(\mathrm{w} / \mathrm{v})$ agar and $3 \%(\mathrm{w} / \mathrm{v})$ sucrose for 15 days, and transferred to Hoagland solution. Seedlings were grown at $22^{\circ} \mathrm{C}$ under long-day conditions (16 h light, $8 \mathrm{~h}$ darkness). Uniformly developed seedlings of DR5::GUS were incubated in water or in solutions containing $10 \mu \mathrm{M}$ IAA, $10 \mu \mathrm{M}$ IAA + $10 \mu \mathrm{M}$ ABA, $10 \mu \mathrm{M}$ IAA + $20 \mu \mathrm{M}$ ABA, $10 \mu \mathrm{M}$ IAA + $50 \mu \mathrm{M}$ ABA, or $10 \mu \mathrm{M}$ IAA $+100 \mu \mathrm{M}$ ABA; $10 \mu \mathrm{M}$ $\mathrm{IAA}+100 \mu \mathrm{M}$ SA, $10 \mu \mathrm{M}$ IAA $+200 \mu \mathrm{M}$ SA, $10 \mu \mathrm{M}$ $\mathrm{IAA}+500 \mu \mathrm{M} \mathrm{SA}$, or $10 \mu \mathrm{M} \mathrm{IAA}+1000 \mu \mathrm{M} \mathrm{SA}$; $10 \mu \mathrm{M}$ IAA + $10 \mu \mathrm{M}$ MeJA, $10 \mu \mathrm{M}$ IAA + $20 \mu \mathrm{M}$ MeJA, $50 \mu \mathrm{M}$ IAA $+10 \mu \mathrm{M}$ MeJA, or $10 \mu \mathrm{M}$ IAA $+100 \mu \mathrm{M}$ $\mathrm{MeJA}$; or $10 \mu \mathrm{M}$ IAA + $10 \mathrm{mM} \mathrm{NaCl}, 10 \mu \mathrm{M}$ IAA + $20 \mathrm{mM} \mathrm{NaCl}, 10 \mu \mathrm{M}$ IAA $+50 \mathrm{mM} \mathrm{NaCl}$, or $10 \mu \mathrm{M}$ IAA + $100 \mathrm{mM} \mathrm{NaCl}$. For low-temperature treatment, seedlings of DR5::GUS incubated with $10 \mu \mathrm{M}$ IAA were transferred to a growth chamber set at $4^{\circ} \mathrm{C}$ under longday conditions.

Micropropagated $M$. sieversii plants were pre-cultured in $1 / 2$ Hoagland nutrient solution for 15 days and then transferred to full-strength Hoagland solution [52]. Plants with heights ranging from 25 to $30 \mathrm{~cm}$ were selected for treatments. Uniformly developed seedlings from the liquid culture were treated with $100 \mu \mathrm{M}$ IAA, $100 \mu \mathrm{M}$ ABA, $50 \mu \mathrm{M}$ $\mathrm{SA}$, or $500 \mu \mathrm{M}$ JA for $3 \mathrm{~h}$, with $150 \mathrm{mM} \mathrm{NaCl}$ for $12 \mathrm{~h}$, or at $4^{\circ} \mathrm{C}$ for $12 \mathrm{~h}$, respectively. Hormones were directly sprayed on the leaf, while $\mathrm{NaCl}$ was added to the Hoagland nutrient solution. For drought treatment, seedlings were exposed to air for $12 \mathrm{~h}$. All seedlings were grown at $25^{\circ} \mathrm{C}$ under a photoperiod of $16 \mathrm{~h}$ light $/ 8 \mathrm{~h}$ dark, except for those grown at low temperatures.

\section{RNA extraction and qRT-PCR analysis}

Total RNA was extracted using the cetyl trimethyl ammonium bromide (CTAB) method [53]. Genomic DNA was removed from total RNA using RNase-free DNase I (TaKaRa Bio, Shiga, Japan). cDNA was synthesized using an M-MLV Reverse Transcriptase Kit (Promega, Madison, WI, USA) according to the manufacturer's protocol, and the Oligo(dT) primers and random primers were used in the reverse-transcription reactions. PCR primer pairs were designed using PREMIER Primer 5 software, and evaluated using DNAMAN V6 software (see Additional file 1). Primer sequences were evaluated using the BLAST program to ensure that the primers would allow amplification of unique and appropriate cDNA segments. All real-time PCR assays generated a single band of the expected size, and therefore accurately represented the expression of the queried gene. Melting curve analysis indicated that all the primers generated a single peak. qRT-PCR was performed in the Applied Biosystems 7500 Real-Time PCR System (Applied Biosystems, Foster, CA, USA), using the UltraSYBR Mixture (CWBIO, Beijing, China). PCR amplification conditions for qRT-PCR were $95^{\circ} \mathrm{C}$ for $10 \mathrm{~min}$, one cycle; and $94^{\circ} \mathrm{C}$ for $10 \mathrm{~s}, 60^{\circ} \mathrm{C}$ for $31 \mathrm{~s}, 45$ cycles. The apple HistoneH3 gene was selected as an internal standard in the analysis. The relative RNA level of each gene was calculated according to the $2^{-\Delta \Delta C T}$ method [54]. Each cDNA sample was quantified in triplicate. The data were visualized with the $\mathrm{R}$ programming language [55].

\section{RT-PCR amplification, cloning, and sequencing}

Total RNA was extracted using the cetyl trimethyl ammonium bromide (CTAB) method [53] from leaves of $M$. sieversii. cDNA was synthesized using the M-MLV Reverse Transcriptase Kit (Promega, Madison, WI, USA) according to the manufacturer's protocol. The primer information is given in Additional file 1. RT-PCR amplification conditions were empirically optimized. The PCR products were cloned into the pMD18-T simple vector (TaKaRa Bio, Shiga, Japan) according to the manufacturer's instructions. The ligated vector DNAs were transformed into Escherichia coli DH5 $\alpha$, transformants were plated on LB plates containing $100 \mu \mathrm{g} / \mathrm{mL}$ ampicillin, and isolated plasmid fragments were then sequenced.

\section{Histochemical analysis of GUS activity}

DR5::GUS seedlings were incubated with GUS staining solution [56] (1 mM of X-Glu, Gold Biotechnology, St. Louis, Missouri, USA; $100 \mathrm{mM}$ sodium phosphate ( $\mathrm{pH}$ 7.5), $10 \mathrm{mM}$ EDTA, $0.5 \mathrm{mM}$ potassium ferrocyanide, $0.5 \mathrm{mM}$ potassium ferricyanide, and $0.1 \%(\mathrm{v} / \mathrm{v})$ Triton X-100) overnight at $37^{\circ} \mathrm{C}$. Samples were washed in a graded ethanol series to extract chlorophyll after GUS staining. Images were taken with an OLYMPUS SZX16-DP72 stereo fluorescence microscope. 


\section{Quantitative analysis of GUS activity}

After growth in Hoagland solution for 10 days, DR5::GUS seedlings were collected and immediately frozen in liquid nitrogen. Total soluble protein was isolated in GUS extraction buffer [56]. The GUS activity of the supernatant was determined using 4-MUG (4-methylumbelliferyl glucuronide) as a substrate. The fluorescence of the GUS-catalyzed hydrolysis reaction product, 4-methylumbelliferone (4MU), was measured with the TECAN GENios system. Protein concentrations in the supernatant were determined by the Bradford method (1976), using bovine serum albumin (BSA) as a standard. GUS activity was expressed as nmol MUG/min/mg protein. Means \pm standard errors (SEs) of three replicates were calculated.

\section{Additional files}

\section{Additional file 1: Real-time PCR primers used to amplify apple HistoneH3 and MdGH3 genes, and RT-PCR amplification primers. Additional file 2: Multiple sequence alignments of full-length MdGH3s. \\ Additional file 3: Pairwise analysis of the overall identities of the full-length MdGH3 protein sequences.}

Additional file 4: Promoter analysis of $\mathrm{MdGH} 3$ genes. Phytohormone and biotic/abiotic stress response elements are listed.

Additional file 5: AtGH3 expression patterns under phytohormone and biotic/abiotic stress.

Additional file 6: Real-time PCR analysis of $M d G H 3$ expression in the leaves and roots of $M$. sieversii.

Additional file 7: Real-time PCR analysis of MdGH3 expression in the leaves and roots of plants subjected to phytohormone and abiotic stress.

Additional file 8: GUS activity assays of whole DR5::GUS transgenic seedlings subjected to phytohormone and abiotic stress treatments.

\section{Competing interests}

The authors declare that they have no competing interests.

\section{Authors' contributions}

HY performed the computational analysis of the GH3 gene family. Experimental procedures were performed by $H Y, K Z, H L, X S, Y L$, and $X L T L$ and $\mathrm{HY}$ conceived the project, analysed the data and wrote the paper. All authors read and approved of the final manuscript.

\section{Acknowledgements}

We gratefully acknowledge the support of The National Natural Science Foundation Project (NO.31171938) and the Special Fund for Agro-scientific Research in the Public Interest (NO.20100302). Furthermore, we thank Fengning Xiang at the Institute of Key Laboratory of Plant Cell Engineering and Germplasm Innovation, School of Life Sciences, Shandong University, for providing Arabidopsis thaliana DR5::GUS seeds.

Received: 21 March 2013 Accepted: 25 April 2013

Published: 2 May 2013

\section{References}

1. Davies PJ: Plant hormones: physiology, biotechnology and molecular biology. London: Kluwer Academic Publishers; 2004.

2. Elisabeth J, Chapman EM: Mechanism of auxin-regulated gene expression in plants. Annu Rev Genet 2009, 43(December):265-285.

3. Okushima Y, Mitina I, Hong L, Quach TA: AUXIN RESPONSE FACTOR 2 (ARF2): a pleiotropic developmental regulator. Plant J 2005, 43(1):29-46.
4. Tsuchisaka A, Theologis A: Unique and overlapping expression patterns among the Arabidopsis 1-amino-cyclopropane-1-carboxylate synthase gene family members. Plant Physiol 2004, 136(2):2982-3000.

5. Riemann M, Riemann M, Takano M: Rice JASMONATE RESISTANT 1 is involved in phytochrome and jasmonate signaling. Plant Cell Environ 2008, 31(6):783-792.

6. Zhang SW, Li CH, Cao J, Zhang YC, Zhang SQ, Xia YF, Sun DY, Sun Y: Altered architecture and enhanced drought tolerance in rice via the down-regulation of indole-3-acetic acid by TLD1/OsGH3.13 activation. Plant Physio/ 2009, 151(4):1889-1901.

7. Frigerio M, Alabadí D, Pérez-Gómez J, García-Cárcel L, Phillips AL, Hedden P, Blázquez MA: Transcriptional regulation of gibberellin metabolism genes by auxin signaling in Arabidopsis. Plant Physiol 2006, 142(2):553-563.

8. Park JE, Park JY, Kim YS, Staswick PE, Jeon J, Yun J, Kim SY, Kim J, Lee YH, Park CM: GH3-mediated auxin homeostasis links growth regulation with stress adaptation response in Arabidopsis. J Biol Chem 2007, 282(13):10036-10046.

9. Shen CJ, Bai YH, Wang SK, Zhang SN, Wu YR, Chen M, Jiang DA, Qi YH: Expression profile of PIN, AUX/LAX and PGP auxin transporter gene families in Sorghum bicolor under phytohormone and abiotic stress. FEBS J 2010, 277(14):2954-2969.

10. Navarro L, Dunoyer P, Jay F, Arnold B, Dharmasiri N, Estelle M, Voinnet O, Jonathan DGJ: A plant miRNA contributes to antibacterial resistance by repressing Auxin signaling. Science 2006, 312(5772):436-439.

11. Hagen G, Guilfoyle TJ: Rapid induction of selective transcription by auxins. Mol Cell Biol 1985, 5(6):1197-1203.

12. Terol J, Domingo C, Talón M: The GH3 family in plants: genome wide analysis in rice and evolutionary history based on EST analysis. Gene 2006, 371(2):279-290.

13. Staswick PE, Tiryaki I, Rowe ML: Jasmonate response locus JAR1 and several related Arabidopsis genes encode enzymes of the firefly luciferase superfamily that show activity on jasmonic, salicylic, and indole-3-acetic acids in an assay for adenylation. Plant Cell 2002, 14(6):1405-1415.

14. Staswick PE, Tiryaki I: The oxylipin signal jasmonic acid is activated by an enzyme that conjugates it to isoleucine in Arabidopsis. Plant Cell 2004 16(8):2117-2127.

15. Staswick PE, Serban B, Rowe M, Tiryaki I, Maldonado MT, Maldonado MC, Suzaa W: Characterization of an Arabidopsis enzyme family that conjugates amino acids to Indole-3-Acetic Acid. Plant Cell 2005, 17(2):616-627

16. Tanaka SI, Mochizuki N, Nagatani A: Expression of the AtGH3a Gene, an Arabidopsis homologue of the soybean $\mathrm{GH} 3$ gene, is regulated by phytochrome B. Plant Cell Physiol 2002, 43(3):281-289.

17. Takase T, Nakazawa M, Ishikawa A, Kawashima M, Ichikawa T, Takahashi N, Shimada H, Manabe K, Matsui M: ydk1-D, an auxin-responsive GH3 mutant that is involved in hypocotyl and root elongation. Plant J 2004, 37(4):471-483.

18. Park JE, Seo PJ, Lee AK, Jung JH, Kim YS, Park CM: An Arabidopsis GH3 gene, encoding an auxin-conjugating enzyme, mediates phytochrome B-regulated light signals in hypocotyl growth. Plant Cell Physiol 2007, 48(8):1236-1241.

19. Wang SK, Bai YH, Shen CJ, Wu YR, Zhang SN, Jiang DA, Guilfoyle TJ, Chen $\mathrm{M}, \mathrm{Qi}$ YH: Auxin-related gene families in abiotic stress response in Sorghum bicolor. Funct Integr Genomics 2010, 10(4):533-546.

20. Domingo C, Andrés F, Tharreau D, Iglesias DJ, Talón M: Constitutive expression of OsGH3.1 reduces auxin content and enhances defense response and resistance to a fungal pathogen in rice. Mol Plant Microbe Interact 2009, 22(2):201-210.

21. Ding XW, Cao YL, Huang LL, Zhao J, Xu CG, Li XH, Wang SP: Activation of the indole-3-acetic acid-amido synthetase $\mathrm{GH} 3-8$ suppresses expansin expression and promotes salicylate- and jasmonate-independent basal immunity in Rice. Plant Cell 2008, 20(1):228-240.

22. Li YN: Researches of Germplasm Resources of Malus Mill. Beijing: China Agriculture Press; 2001:20-23. in Chinese with an English abstract.

23. Chen XS, Feng T, Zhang YM, He TM, Feng JR, Zhang CY: Genetic diversity of volatile components in Xinjiang wild apple (Malus sieversii). J Genet Genomics 2007, 34(2):171-179.

24. Böttcher C, Keyzers RA, Boss PK, Davies C: Sequestration of auxin by the indole-3-acetic acid-amido synthetase GH3-1 in grape berry (Vitis vinifera L.) and the proposed role of auxin conjugation during ripening. J Exp Bot 2010, 61(13):3615-3625. 
25. Devoghalaere F, Doucen T, Guitton B, Keeling J, Payne W, Ling TJ, Ross JJ, Hallett LC, Gunaseelan K, Dayatilake DA, Diak R, Breen KC, Tustin DS, Costes E, Chagné D, Schaffer RJ, David KM: A genomics approach to understanding the role of auxin in apple (Malus $\times$ domestica) fruit size control. BMC Plant Biol 2012, 12(7):1-15

26. Ulmasov T, Hagen G, Guilfoyle TJ: ARF1, a transcriptionfactor that binds auxin response elements. Science 1997, 276(5320):1865-1868.

27. Casimiro I, Marchant A, Bhalerao RP, Beeckman T, Dhooge S, Swarup R Graham N, Inzé D, Sandberg G, Casero PJ, Bennett M: Auxin transport promotes Arabidopsis lateral root initiation. Plant Cell 2001, 13(4):843-852.

28. Liu ZB, Ulmasov T, Shi X, Hagen G, Guilfoyle TJ: The soybean GH3 promoter contains multiple auxin-inducible elements. Plant Cell 1994, 6(5):645-657.

29. Ulmasov T, Liu ZB, Hagen G, Guilfoyle TJ: Composite structure of auxin response elements. Plant Cell 1995, 7(10):1611-1623.

30. Oono Y, Chen QG, Overvoorde PJ, Kohler C, Theologis A: Age mutants of Arabidopsis exhibit altered auxin-regulated gene expression. Plant Cell 1998, 10(10):1649-1662.

31. Ulmasov T, Murfett J, Hagen G, Guilfoyle TJ: Aux/IAA proteins repress expression of reporter genes containing natural and highly active synthetic auxin response elements. Plant Cell 1997, 9(11):1963-1971.

32. Sabatini S, Beis D, Wolkenfelt H, Murfett J, Guilfoyle T, Malamy J, Benfey P, Leyser O, Bechtold N, Weisbeek P: An auxin-dependent distal organizer of pattern and polarity in the Arabidopsis root. Cell 1999, 99(5):463-472.

33. Casimiro I, Marchant A, Bhalerao RP, Beeckman T, Dhooge S, Swarup R, Graham N, Inzé D, Sandberg G, Casero PJ: Auxin transport promotes Arabidopsis lateral root initiation. Plant Cell 2001, 13(4):843-852.

34. Velasco R, Zharkikh A, Affourtit J, Dhingra A, Cestaro A, Kalyanaraman A, Fontana P, Bhatnagar SK, Troggio M, Pruss D, Salvi S, Pindo M, Baldi P, Castelletti S, Cavaiuolo M, Coppola G, Costa F, Cova V, Dal Ri A, Goremykin V, Komjanc M, Longhi S, Magnago P, Malacarne G, Malnoy M, Micheletti D, Moretto M, Perazzolli M, Si-Ammour A, Vezzulli S, et al: The genome of the domesticated apple (Malusxdomestica Borkh.). Nat Genet 2010, 42(10):833-839.

35. Jain M, Kaur N, Tyagi AK, Khurana JP: The auxin-responsive GH3 gene family in rice (Oryza sativa). Funct Integr Genomics 2006, 6(1):36-46.

36. Hagen G, Guilfoyle TJ: Auxin-responsive gene expression: genes, promoters and regulatory factors. Plant Mol Biol 2002, 49(3-4):373-385.

37. Felton GW, Korth KL: Trade-offs between pathogen and herbivore resistance. Curr Opin Plant Biol 2000, 3(4):309-314.

38. Feys BJ, Parker JE: Interplay of signaling pathways in plant disease resistance. Trends Genet 2000, 16(10):449-456.

39. Pieterse CMJ, Ton J, Van Loon LC: Cross-talk between plant defense signaling pathways: Boost or burden? Agbiotechnet 2001, 3(June):1-8

40. Jain M, Khurana JP: Transcript profiling reveals diverse roles of auxinresponsive genes during reproductive development and abiotic stress in rice. FEBS J 2009, 276(11):3148-3162.

41. Wang D, Pajerowska-Mukhtar K, Culler AH, Dong XN: Salicylic acid inhibits pathogen growth in plants through repression of the Auxin signaling pathway. Curr Biol 2007, 17(20):1784-1790.

42. Seo PJ, Xiang FN, Qiao M, Park JY, Lee YN, Kim SG, Lee YH, Park WJ, Park CM: The MYB96 transcription factor mediates Abscisic Acid signaling during drought stress response in Arabidopsis. Plant Physiol 2009, 15(1):275-289

43. Eddy SR: Profile hidden Markov models. Bioinformatics 1998, 14(9):755-763.

44. Guo AY, Zhu QH, Chen X, Luo JC: GSDS: a gene structure display server. Hereditas (Beijing) 2007, 9(8):1023-1026.

45. Soderlund C, Nelson W, Shoemaker A, Paterson A: SyMAP: A system for discovering and viewing syntenic regions of FPC maps. Genome Res 2006, 16(9):1159-1168

46. Krzywinski M, Schein J, Birol I, Connors J, Gascoyne R, Horsman D, Jones SJ, Marra MA: Circos: An information aesthetic for comparative genomics. Genome Res 2009, 19(9):1639-1645.

47. Li KB: ClustalW-MPI: ClustalW analysis using distributed and parallel computing. Bioinformatics 2003, 19(12):1585-1586.

48. Tamura K, Peterson D, Peterson N, Stecher G, Nei M, Kumar S: MEGA5: Molecular evolutionary genetics analysis using maximum likelihood, evolutionary distance, and maximum parsimony methods. Mol Biol Evol 2011, 28(10):2731-2739.

49. Brazma A, Parkinson H, Sarkans U, Shojatalab M, Vilo J, Abeygunawardena N, Holloway E, Kapushesky M, Kemmeren P, Lara GG: ArrayExpress-a public repository for microarray gene expression data at the EBI. Nucleic Acids Res 2003, 31(1):68-71.

50. Edgar R, Domrachev M, Lash AE: Gene Expression Omnibus: NCBI gene expression and hybridization array data repository. Nucleic Acids Res 2002, 30:207-210

51. Zimmermann P, Matthias HH, Hennig L, Gruissem W: GENEVESTIGATOR. Arabidopsis microarray database and analysis toolbox. Plant Physiol 2004, 136(1):12621-2632.

52. Zhao XJ, Lei HJ, Zhao K, Yuan HZ, Li TH: Isolation and characterization of a dehydration responsive element binding factor MsDREBA5 in Malus sieversii Roem. Sci Hortic 2012, 142(July):212-220.

53. Chang SJ, Puryear J, Cairney J: A simple and efficient method for isolating RNA from pine trees. Plant Mol Biol Rep 1993, 11(2):113-116.

54. Livak KJ, Schmittgen TD: Analysis of relative gene expression data using real-time quantitative PCR and the $2_{T}^{-\Delta \Delta C}$ Method. Methods 2001, 25(4):402-408.

55. Grunsky EC: R: a data analysis and statistical programming environmentan emerging tool for the geosciences. Comput Geosci 2002, 28(10):1219-1222

56. Jefferson RA, Kavanagh TA, Bevan MW: GUS fusions: beta-glucuronidase as a sensitive and versatile gene fusion marker in higher plants. EMBO J 1987, 6(13):3901-3907

doi:10.1186/1471-2164-14-297

Cite this article as: Yuan et al:: Genome-wide analysis of the GH3 family in apple (Malus $\times$ domestica). BMC Genomics 2013 14:297.

\section{Submit your next manuscript to BioMed Central and take full advantage of:}

- Convenient online submission

- Thorough peer review

- No space constraints or color figure charges

- Immediate publication on acceptance

- Inclusion in PubMed, CAS, Scopus and Google Scholar

- Research which is freely available for redistribution 